\title{
UJI FITOKIMIA DAN AKTIVITAS ANTIOKSIDAN EKSTRAK METANOL DAGING BUAH MAHKOTA DEWA (PHALERIA MACROCARPA)
}

\author{
Rosalina Y. Kurang ${ }^{(1)}$ dan Naomi A. Malaipada ${ }^{\left({ }^{2}\right)}$ \\ ${ }^{1,2}$ Kimia, Universitas Tribuana Kalabahi \\ ${ }^{1,2}$ Kalabahi, Alor - Nusa Tenggara Timur, 85813 \\ E-mail : rosalinayuliana89@gmail.com ${ }^{1)}$, naomimalaipada.kimiauntrib@gmail.com ${ }^{2)}$
}

\begin{abstract}
ABSTRAK
Mahkota dewa (Phaleria macrocarpa) merupakan tanaman perdu yang berasal dari family Thymelaceae. Senyawa bioaktif yang terkandung di dalam tanaman ini dapat digunakan sebagai obat. Penelitian ini bertujuan untuk mengetahui kandungan golongan senyawa dan aktivitas antioksidan ekstrak metanol daging buah mahkota dewa. Metode yang digunakan dalam penelitian ini yaitu ekstraksi dengan pelarut metanol dan metode 1,1-difenil-2-pikrilhidrazyl (DPPH) untuk uji aktivitas antioksidan. Hasil penelitian menunjukkan bahwa ekstrak metanol daging buah mahkota dewa mengandung golongan senyawa flavonoid, alkaloid, terpenoid dan fenolik. Uji aktivitas antioksidan memberikan nilai $\mathrm{IC}_{50}$ sebesar 127,983 ppm dengan kategori antioksidan sedang.
\end{abstract}

Kata Kunci: Mahkota Dewa (Phaleria Macrocarpa), Ekstraksi, Metode DPPH, Fitokimia, Antioksidan

\section{PENDAHULUAN}

Penggunaan tanaman herbal sebagai obat sudah dilakukan secara turun-temurun dari dahulu kala. Bagian tanaman yang digunakan sebagai obat yaitu akar, batang daun, buah, daging buah, kulit batang maupun kulit buah. Salah satu tanaman yang digunakan sebagai tanaman obat yaitu mahkota dewa (Phaleria macrocarpa). Tanaman mahkota dewa adalah tanaman perdu yang berasal dari family Thymelaceae. Tanaman ini tumbuh di daerah dengan ketinggian 10-1.200 meter dari permukaan laut, dan tinggi tumbuhan ini bisa mencapai 5 meter (Fiana dan Oktaria, 2016).

Manfaat mahkota dewa sebagai obat dapat dilihat dari kandungan kimianya. Kandungan bahan aktif yang terdapat pada tanaman mahkota dewa yaitu mineral, vitamin $\mathrm{C}$, vitamin $\mathrm{E}$, alkaloid, flavonoid, polifenol dan saponin (Candrarisna dan Kurnianto, 2018). Alkaloid bersifat detoksifikasi, dapat menetralisasi racun di dalam tubuh. Saponin bermanfaat sebagai antibakteri dan antivirus, mengurangi kadar gula darah, mengurangi penggumpalan darah. Flavonoid berfungsi sebagai antioksidan dan polifenol yang berfungsi sebagai antihistamin (Fiana dan Oktaria, 2016). Tanaman Mahkota dewa juga bermanfaat sebagai obat kanker, obat diabetes, batu ginjal, antidiare dan kegunaan lain yaitu sebagai teh fungsional dan juga sebagai penambah stamina (Candrarisna dan Kurnianto, 2018).

Ekstrak etanol daging buah mahkota dewa mampu meningkatkan viabilitas sel limfosit terhadap paparan $\mathrm{H}_{2} \mathrm{O}_{2}$ 3\% (Yulianti dan Arijana, 2016). Kandungan saponin dalam buah mahkota dewa dapat menurunkan kadar glukosa darah (Fiana dan Oktaria, 2016). Ekstrak buah mahkota dewa dapat menurunkan kadar glukosa darah pada tikus diabetes (Arjadi dan Mustofa, 2017).
Ekstrak kulit buah mahkota dewa dapat digunakan sebagai terapeutika diabetes mellitus tipe-1 pada tikus putih yang di induksi aloksan (Candrarisna dan Kurnianto, 2018).

Tumbuhan yang mengandung senyawa bioaktif seperti flavonoid, alkaloid, terpenoid, vitamin $\mathrm{C}$, dan vitamin $\mathrm{E}$ merupakan bahan baku yang berpotensi sebagai antioksidan alami (Purwanto dkk., 2017). Golongan senyawa yang mengandung antioksidan dapat berpotensi dijadikan sebagai minuman dan makanan fungsional (Sukainah dkk., 2017). Salah satu cara untuk menghilangkan rasa pahit pada buah mahkota dewa sehingga dapat digunakan sebagai teh fungsional yaitu dengan menambahkan daun stevia (Yulianti dan Arijana, 2016).

Antioksidan merupakan senyawa yang dapat menghambat reaksi oksidasi dengan mengikat radikal bebas dan molekul yang sangat reaktif sehingga kerusakan sel dapat dihambat. Antioksidan dapat menghentikan reaksi berantai dengan menghilangkan zat antara radikal bebas, dan menghambat reaksi oksidasi lainnya (Vijayanand dan Thomas., 2016). Ketika antioksidan menetralkan radikal bebas dengan menerima atau menyumbangkan elektron, antioksidan tidak akan berubah menjadi radikal bebas dan tetap stabil.

Antioksidan memiliki peran penting untuk menjaga kesehatan. Hal ini disebabkan oleh kemampuan antioksidan dalam menangkap radikal bebas. Apabila tubuh manusia tidak punya cadangan antioksidan berlebih maka tubuh membutuhkan antioksidan. Fungsi antioksidan adalah menetralisasi radikal bebas, sehingga tubuh terlindungi dari berbagai penyakit degeneratif dan kanker (Agustina dkk., 2017). Salah satu metode yang 
digunakan untuk uji aktivitas antioksidan adalah metode 1,1-difenil-2-pikrilhidrazil (DPPH).

DPPH merupakan radikal bebas yang stabil pada suhu kamar dan sering digunakan untuk mengevaluasi aktivitas antioksidan beberapa senyawa atau ekstrak bahan alam. DPPH menerima elektron atau radikal hidrogen akan membentuk molekul diamagnetik yang stabil. Radikal bebas merupakan suatu senyawa atau molekul yang memiliki satu atau lebih elektron tidak berpasangan menyebabkan senyawa tersebut sangat reaktif mencari pasangan, dengan mengikat elektron molekul yang berada di sekitarnya.

Radikal bebas dapat berasal dari dalam tubuh sebagai bagian dari hasil proses metabolisme. Sedangkan radikal bebas yang bersumber dari luar tubuh dapat disebabkan oleh faktor lingkungan, termasuk kebiasaan merokok, penggunaan pestisida pada makanan, polusi dan radiasi (Mbaoji dkk., 2016).

Salah satu daerah yang memiliki tanaman Mahkota dewa yaitu Desa Alim Mebung, Kabupaten Alor. Berdasarkan hasil survei tentang pemanfaatan tanaman mahkota dewa, salah satu masyarakat menyebutkan bahwa daging buah mahkota dewa digunakan sebagai minuman teh sebelum melakukan aktivitas pagi dan sesudah melakukan aktivitas. Kandungan fitokimia yang ada pada tanaman tersebut yang menjadikannya dapat digunakan sebagai minuman seduh. Pemanfaatan tanaman mahkota dewa belum banyak di ketahui sehingga tanaman ini di biarkan tumbuh liar. Jika dilihat dari segi khasiatnya, manfaat mahkota dewa sangatlah besar sehingga diperlukan pengolahan tanaman tersebut.

Meskipun penelitian tentang uji komposisi kimia dan bioaktivitas dari tanaman mahkota dewa telah banyak dilakukan, tetapi secara kemotaksonomi perbedaan iklim tempat tumbuh suatu tumbuhan akan mempengaruhi komposisi kandungan senyawa kimia dari suatu tanaman (Munte dan Lubis, 2016). Pemilihan pelarut metanol untuk proses ekstraksi dikarenakan pelarut metanol merupakan pelarut universal yang dapat menarik analit-analit yang bersifat polar maupun nonpolar. Selain itu belum pernah dilaporkan hasil penelitian tentang tanaman Mahkota dewa dari daerah ini. Oleh karena itu pada penelitian dilakukan uji fitokimia dan aktivitas antioksidan ekstrak metanol daging buah mahkota dewa-

\section{RUANG LINGKUP}

Permasalahan dalam penelitian ini mencakup:

1. Bagaimana hasil uji fitokimia dan aktivitas antioksidan ekstrak metanol daging buah mahkota dewa (Phaleria macrocarpa)

2. Penelitian ini di batasi pada uji fitokimia dan aktivitas antioksidan ekstrak metanol daging buah mahkota dewa (Phaleria macrocarpa)

3. Hasil penelitian ini diharapkan dapat memberikan informasi ilmiah tentang kandungan golongan senyawa dan aktivitas antioksidan tanaman mahkota dewa (Phaleria macrocarpa) dan potensinya sebagai tanaman obat.

\section{BAHAN DAN METODE}

Penelitian ini bersifat eksperimental laboratorium dengan beberapa tahapan uji.

\subsection{Bahan dan Alat}

Bahan-bahan yang digunakan adalah buah mahkota dewa yang matang diperoleh dari Desa Alim Mebung, metanol PA Merck, asam sulfat pekat Merck, asam klorida, besi (III) klorida, serbuk magnesium, raksa (II) klorida, 1,1-difenil-2-pikrilhidrazyl (DPPH), asam askorbat, aquades, kloroform, pereaksi Meyer, aluminium foil, kertas saring.

Alat-alat yang digunakan yaitu spektrofotometer UVVis, evaporator, timbangan analitis, vortex inkubator, tabung reaksi, pipet, blender, saringan dan mikro pipet.

\subsection{Prosedur Kerja}

1. Preparasi sampel

Sampel yang digunakan adalah buah mahkota dewa Sampel diambil dan dicuci bersih. Buah mahkota dewa dibuang biji dan cangkangnya sehingga tersisa daging buah. Daging buah dipotong tipis-tipis kemudian dikeringkan. Sampel yang kering dihaluskan menggunakan blender hingga menjadi serbuk.

2. Ekstraksi

Serbuk daging buah mahkota dewa ditimbang sebanyak 250 gr dan di maserasi menggunakan pelarut metanol 2 L selama 24 jam, disaring dengan kertas saring. Filtrat yang diperoleh di evaporasi sehingga diperoleh ekstrak pekat daging buah mahkota dewa.

3. Uji Fitokimia (Khotimah, 2016).

Beberapa tes fitokimia yang dilakukan adalah

1) Uji alkaloid

Sebanyak $1 \mathrm{mg}$ ekstrak ditambahkan $3 \mathrm{~mL}$ kloroform dan 3 tetes pereaksi Meyer. Endapan putih yang terbentuk menunjukkan adanya alkaloid.

2) Uji flavonoid

Sebanyak $1 \mathrm{mg}$ ekstrak ditambahkan $3 \mathrm{~mL}$ etanol dan dipanaskan. Setelah larut, ditambahkan 5 gr serbuk $\mathrm{Mg}$ dan 3 tetes $\mathrm{HCl}$ pekat. Terbentuknya warna kuning, jingga atau merah menunjukkan adanya flavonoid.

3) Uji terpenoid

Sebanyak $1 \mathrm{mg}$ ekstrak dilarutkan dalam $3 \mathrm{~mL}$ kloroform dan $5 \mathrm{~mL}$ larutan $\mathrm{H}_{2} \mathrm{SO}_{4}$ pekat melalui dinding tabung reaksi. Adanya terpenoid ditunjukkan dengan terbentuknya warna cokelat kemerahan.

4) Uji fenolik

Sebanyak $1 \mathrm{mg}$ ekstrak ditambahkan $1 \mathrm{~mL}$ $\mathrm{FeCl}_{3} 1 \%$. Terbentuknya warna hitam kebiruan menunjukkan adanya fenol. 
5) Uji Antioksidan

Pengujian aktivitas antioksidan dilakukan dengan metode DPPH. Pembuatan larutan DPPH dengan konsentrasi $6 \times 10^{-5} \mathrm{M}$ dibuat dengan menimbang $1,182 \mathrm{mg}$ DPPH dan dilarutkan ke dalam $50 \mathrm{~mL}$ metanol. Pembuatan larutan uji 500 ppm dilakukan dengan melarutkan 0,05 gr ekstrak buah mahkota dewa ke dalam $100 \mathrm{~mL}$ metanol. Kemudian diencerkan menjadi 250 ppm, 125 ppm, dan 50 ppm dan 25 ppm. Larutan uji di pipet sebanyak 33,33 $\mu \mathrm{L}$ dan kemudian dimasukkan ke dalam tube yang terlindung dari cahaya, kemudian ditambahkan $1 \mathrm{~mL}$ DPPH. Campuran larutan tersebut diaduk menggunakan alat vortex inkubator selama 10 detik atau hingga homogen. Selanjutnya, larutan di inkubasi pada suhu $30^{\circ} \mathrm{C}$ selama 30 menit. Larutan DPPH radikal akan berubah warna dari ungu menjadi kuning pucat selama proses reduksi oleh antioksidan. Penurunan absorbansi ini diukur dengan spektrofotometer UV pada panjang gelombang $515 \mathrm{~nm}$ (As). Larutan blanko yang digunakan sebanyak 33,33 $\mu$ L. DPPH sebanyak $1 \mathrm{~mL}$ dalam metanol yang diukur pada panjang gelombang sama (Ab). Asam askorbat digunakan sebagai kontrol positif.

Perlakuan pada uji DPPH ini dilakukan sebanyak 3 kali pengulangan (triplo). Aktivitas penghambat radikal dapat dihitung dengan menggunakan persamaan (1).

$$
\% \text { inhibisi }=((\mathrm{Ab}-\mathrm{As})) / \mathrm{Ab} \times 100 \%
$$

Ket. (1)

$\mathrm{Ab}=$ Absorbansi blanko

As $=$ Absorbansi sampel

Setelah diperoleh persentase inhibisi dari masingmasing konsentrasi, selanjutnya hasil perhitungan dimasukkan ke dalam persamaan regresi dengan konsentrasi ekstrak (ppm) sebagai absis (sumbu $\mathrm{x}$ ) dan nilai \% inhibisi (antioksidan) sebagai koordinat nya (sumbu y). Dari persamaan $\mathrm{y}=\mathrm{a}+\mathrm{bx}$, dapat dihitung nilai $\mathrm{IC}_{50}$. Nilai $\mathrm{IC}_{50}$ didapatkan dari nilai $\mathrm{x}$ setelah mengganti $\mathrm{y}=50$ (Molyneux, 2004).

\section{PEMBAHASAN}

Ekstraksi daging buah mahkota dewa dilakukan menggunakan metode maserasi dengan pelarut metanol. Pemilihan pelarut metanol dikarenakan pelarut metanol merupakan pelarut universal yang memiliki gugus polar $(-\mathrm{OH})$ dan gugus nonpolar $\left(-\mathrm{CH}_{3}\right)$ sehingga dapat menarik analit-analit yang bersifat polar maupun non polar. Hasil ekstraksi diperoleh ekstrak pekat daging buah mahkota dewa sebesar 10 gram.

Uji fitokimia dilakukan untuk mengidentifikasi golongan senyawa yang terkandung dalam sampel tanaman yang diteliti. Metode skrining fitokimia dilakukan dengan melihat reaksi pengujian warna dengan menggunakan suatu pereaksi warna (Khotimah, 2016). Uji golongan senyawa dilakukan pada ekstrak daging buah mahkota dewa dengan ditandai adanya perubahan warna sebagai uji positifnya. Hasil uji fitokimia terhadap ekstrak metanol daging buah mahkota dewa dapat dilihat pada Tabel 1.

\section{Tabel 1. Hasil uji kualitatif fitokimia Ekstrak} metanol daging buah mahkota dewa (Phaleria microcarpa)

\begin{tabular}{|c|c|}
\hline & \\
\hline Flavonoid & + \\
\hline Alkaloid & + \\
\hline Terpenoid & + \\
\hline Fenolik & + \\
\hline
\end{tabular}

Berdasarkan Tabel 1 diketahui bahwa daging buah mahkota dewa memiliki kandungan golongan senyawa flavonoid, alkaloid, terpenoid dan fenolik.

Uji flavonoid dilakukan dengan menggunakan pereaksi serbuk magnesium $(\mathrm{Mg})$ dan asam klorida pekat (HCl). Penambahan serbuk $\mathrm{Mg}$ bertujuan agar membentuk ikatan dengan gugus karbonil pada senyawa flavonoid. Penambahan $\mathrm{HCl}$ bertujuan untuk membentuk garam flavilium yang ditandai dengan perubahan warna menjadi merah (Parwati dkk., 2014). Hasil uji terhadap golongan senyawa flavonoid menunjukkan hasil positif dengan terbentuknya warna merah. Warna yang terbentuk menunjukkan bahwa secara kualitatif kandungan flavonoid pada ekstrak metanol daging buah mahkota dewa adalah positif $(+)$.

Uji alkaloid dilakukan menggunakan pereaksi Mayer (kalium tetraiodomerkurat). Sampel yang mengandung alkaloid akan membentuk endapan putih bila di reaksi dengan pereaksi Mayer. Hasil uji alkaloid menunjukkan endapan putih yang berarti bahwa secara kualitatif kandungan alkaloid pada ekstrak metanol daging buah mahkota dewa adalah positif (+). Flavonoid termasuk senyawa fenolik alam yang potensial sebagai antioksidan dan mempunyai bioaktifitas sebagai obat.

Garam alkaloid berbeda sifatnya dengan alkaloid dalam wujud basa. Alkaloid dalam wujud basa tidak larut dalam air tetapi mudah larut dalam pelarut organik (seperti benzena, eter, kloroform) sedangkan dalam bentuk garamnya, alkaloid mudah larut dalam pelarut polar (Endarini, 2016). Dengan demikian maka kandungan senyawa alkaloid di dalam ekstrak daging buah mahkota dewa merupakan senyawa alkaloid dalam wujud garamnya karena reaksi positif ditunjukkan pada pelarut yang bersifat polar.

Golongan senyawa terpenoid pada ekstrak metanol daging buah mahkota dewa menunjukkan hasil positif dengan dihasilkannya warna cokelat. Warna yang dihasilkan merupakan reaksi antara asam sulfat yang ditambahkan ke dalam ekstrak yang telah diencerkan 
dengan kloroform. Hasil uji terpenoid menunjukkan warna cokelat yang berarti bahwa secara kualitatif kandungan terpenoid pada ekstrak metanol daging buah mahkota dewa adalah positif $(+)$.

Senyawa fenolik adalah senyawa yang terdiri dari cincin aromatik dengan gugus hidroksi $(-\mathrm{OH})$ satu atau lebih. Hasil uji terhadap golongan senyawa fenol menunjukkan hasil positif dengan terbentuknya warna biru kehitaman. Warna yang terbentuk dikarenakan gugus fenol pada senyawa fenolik membentuk kompleks dengan ion $\mathrm{Fe}^{3+}$ dari $\mathrm{FeCl}_{3}$. Dengan terbentuknya warna biru kehitaman maka secara kualitatif kandungan fenolik pada ekstrak metanol daging buah mahkota dewa adalah positif (+). Senyawa golongan fenol berperan sebagai antioksidan, semakin besar kandungan senyawa golongan fenol maka semakin besar aktivitas antioksidan nya.

Kandungan fitokimia pada suatu tanaman sangat dipengaruhi oleh tempat tumbuh tanam tersebut. Selain itu dipengaruhi oleh faktor internal maupun eksternal. Faktor internal seperti gen dan faktor eksternal diantaranya seperti cahaya, suhu, kelembaban, $\mathrm{pH}$, kandungan unsur hara di dalam tanah dan ketinggian tempat. Dengan demikian maka diduga perbedaan tempat tumbuh akan berpengaruh terhadap pertumbuhan dan perkembangan tanaman. Akibatnya proses metabolisme pada tanaman tersebut juga akan terganggu sehingga kandungan senyawa yang dihasilkan juga akan berbeda secara kuantitatif. Buah mahkota dewa mengandung flavonoid, alkaloid, steroid dan fenolik yang ditandai dengan parsial positif (+), sedangkan tidak mengandung terpenoid dan saponin (Ma'ruf, 2017). Selain itu , buah mahkota dewa mengandung flavonoid, fenol, minyak atsiri, lignin, sterol, alkaloid, dan tannin (Harmanto, 2005; Yulianti, 2016).

Uji aktivitas antioksidan dilakukan dengan menggunakan metode DPPH (1,1-difenil-2-pikril hidrazil). Pemilihan metode ini dikarenakan cepat, akurat, efektif, praktis serta hanya memerlukan sedikit sampel. Hasil reaksi antara DPPH dengan senyawa antioksidan dapat diketahui melalui perubahan warna DPPH dari ungu pekat menjadi kuning yang terjadi akibat donasi proton yang dilakukan oleh antioksidan bahan alam kepada DPPH. Perubahan warna ini dijadikan sebagai patokan pengukuran pada spektrofotometer cahaya tampak (Molyneaux, 2004).

Kemudahan metode ini adalah dapat digunakan baik untuk sample berwarna juga untuk sample tak berwarna. Hal ini sesuai dengan kebutuhan dalam pengujian aktivitas antioksidan, dimana senyawa atau DPPH berperan sebagai radikal bebas dalam metanol berwarna ungu tua yang terdeteksi pada panjang gelombang $517 \mathrm{~nm}$, akan bereaksi dengan senyawa antioksidan sehingga DPPH akan berubah menjadi 1,1-diphenyl-2-picrylhydrazin yang bersifat non-radikal. Pengukuran penangkapan radikal DPPH menggunakan spektrofotometri UV-Vis akan diketahui nilai aktivitas perendaman radikal bebas yang dinyatakan dengan $\mathrm{IC}_{50}$.

Setelah diperoleh hasil pengukuran absorbansi menggunakan spektrofotometer UV-Vis, dilakukan perhitungan untuk mencari persen perendaman ( $\%$ inhibisi). Persen inhibisi ekstrak metanol daging buah mahkota dewa (Phaleria microcarpa) dapat dilihat pada Tabel 2.

Tabel 2. Persen inhibisi ekstrak metanol daging buah mahkota dewa (Phaleria microcarpa)

\begin{tabular}{|c|c|}
\hline Konsentrasi $(\mathrm{ppm})$ & \% Inhibisi \\
\hline 25 & 15,616 \\
\hline 50 & 24,728 \\
\hline 125 & 54,663 \\
\hline 250 & 85,683 \\
\hline
\end{tabular}

Setelah diperoleh \% inhibisi maka dibuatlah kurva hubungan antara \% inhibisi dan konsentrasi sampel uji maka akan diperoleh persamaan regresi linear $\mathrm{y}=\mathrm{ax}+\mathrm{b}$ untuk menghitung nilai $\mathrm{IC}_{50}$. Grafik hubungan konsentrasi sampel dan \% inhibisi dapat dilihat pada Gambar 1

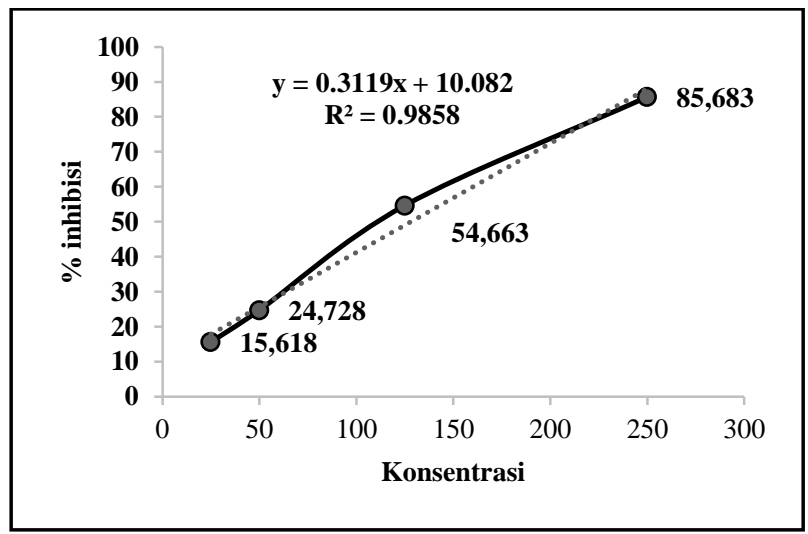

\section{Gambar 1. Kurva regresi penetapan $\mathrm{IC}_{50}$ daging} buah mahkota dewa (Phaleria microcarpa)

Nilai IC $_{50}$ ekstrak metanol daging buah mahkota dewa didapat dari hasil perhitungan persamaan regresi y $=\mathrm{ax}+\mathrm{b}$. Koefisien y pada persamaan ini adalah sebagai IC sedangkan koefisien $x$ pada persamaan ini adalah konsentrasi dari ekstrak yang akan dicari nilainya, di mana nilai dari $\mathrm{x}$ yang didapat merupakan besarnya konsentrasi yang diperlukan untuk dapat meredam $50 \%$ aktivitas radikal DPPH. Nilai R yang nilainya mendekati +1 (bernilai positif) menunjukkan bahwa semakin tinggi konsentrasi ekstrak maka semakin tinggi pula aktivitas antioksidan nya (Artanti dan Lisnasari, 2018). Semakin tinggi konsentrasi larutan uji maka semakin banyak proton yang disumbangkan kepada 1,1-difenil-2pikrilhidrasil (DPPH) atau semakin banyak radikal bebas dari DPPH yang dapat di netralkan (Mangiwa, 2019). Berdasarkan hasil perhitungan, diperoleh nilai $\mathrm{IC}_{50}$ 
ekstrak metanol daging buah mahkota dewa (Phaleria microcarpa) yaitu 127,983 ppm.

Menurut Putri dan Hidajati (2015), klasifikasi antioksidan dibagi menjadi 5 , yaitu $<50 \mathrm{ppm}$ (sangat kuat), 50-100 ppm (kuat), 100-150 ppm (sedang), 150200 ppm (lemah) dan >200 ppm adalah sangat lemah. Dari nilai $\mathrm{IC}_{50}$ ekstrak metanol daging buah mahkota dewa yang diperoleh maka memiliki aktivitas antioksidan yang sedang. Semakin tinggi kadar flavonoid maka semakin tinggi antioksidan nya. Senyawa yang berpotensi sebagai antioksidan yaitu flavonoid dan fenolik. Flavonoid merupakan senyawa polifenol mempunyai kemampuan untuk menyumbangkan atom hidrogen kepada senyawa radikal bebas, maka aktivitas antioksidan senyawa polifenol dapat dihasilkan pada reaksi netralisasi radikal bebas atau pada penghentian reaksi berantai yang terjadi. Kemampuan dari flavonoid untuk kompleks dengan ion logam seperti besi yang memungkinkan menambah efek antioksidan nya.

Kontrol positif yang digunakan pada uji aktivitas antioksidan adalah asam askorbat. Asam askorbat merupakan antioksidan yang larut dalam air. Penggunaan kontrol positif yaitu untuk mengetahui seberapa kuat potensi antioksidan yang ada pada ekstrak metanol daging buah mahkota dewa jika dibandingkan dengan asam askorbat. Dari hasil pengujian menunjukkan bahwa aktivitas antioksidan asam askorbat mempunyai nilai $\mathrm{IC}_{50}$ sebesar 2,666 ppm. Hasil uji menunjukkan bahwa asam askorbat memiliki antioksidan sangat kuat bila dibandingkan dengan ekstrak metanol daging buah mahkota dewa. Asam askorbat memiliki aktivitas antioksidan sangat kuat dikarenakan memiliki 2 gugus hidroksi (-OH) pada ikatan rangkapnya yang mudah mengalami oksidasi oleh radikal bebas, selain itu asam askorbat tidak melalui proses ekstraksi dan fraksinasi sehingga aktivitas antioksidan yang diperoleh lebih tinggi (Kumalaningsih, 2006).

Pada penelitian ini, aktivitas antioksidan berdasarkan penangkapan radikal DPPH memiliki hubungan dengan kandungan fenolik dan flavonoid yang ada pada tanaman mahkota dewa (Phaleria microcarpa). Senyawa fenolik yang terkandung dalam daging buah mahkota dewa memiliki kemampuan sebagai antioksidan karena pada strukturnya terdapat gugus hidroksil yang dapat mendonorkan atom hidrogennya kepada radikal bebas sehingga radikal senyawa fenolik dapat meredam radikal bebas. Flavonoid merupakan senyawa pereduksi yang dapat menghambat banyak reaksi oksidasi. Flavonoid memiliki kemampuan sebagai antioksidan karena mampu mentransfer sebuah elektron kepada senyawa radikal bebas.

Antioksidan dapat melindungi tubuh dari sejumlah penyakit yang ditimbulkan radikal bebas. Saat ini, penggunaan antioksidan alami lebih dipilih karena dianggap lebih aman dibandingkan antioksidan sintesis, karena antioksidan alami berasal dari ekstrak tanaman. Buah mahkota dewa merupakan salah satu sumber antioksidan yang mudah dibudidayakan di Indonesia, di mana pada daging buahnya memiliki kandungan senyawa flavonoid sebagai zat antioksidan yang paling tinggi. Selain flavonoid, pada daging buah Mahkota dewa juga mengandung fenol, minyak asiri, lignin, sterol, alkanoid, dan tannin (Harmanto, 2005 dalam Yulianti, 2016).

Senyawa-senyawa fenol mempunyai aktivitas antioksidan karena sifat-sifat redoks nya. Semakin banyak gugus hidroksi yang terikat pada senyawa flavonoid dan fenolik yang ada pada sampel uji maka kandungan antioksidan nya akan semakin tinggi. Apabila nilai $\mathrm{IC}_{50}$ sampel sama atau mendekati nilai $\mathrm{IC}_{50}$ kontrol positif maka dapat dikatakan bahwa berpotensi sebagai salah satu alternatif antioksidan yang sangat kuat.

\section{KESIMPULAN}

Kandungan senyawa fitokimia yang terdapat dalam ekstrak metanol daging buah mahkota yaitu flavonoid, alkaloid, terpenoid dan fenolik. Nilai $\mathrm{IC}_{50}$ ekstrak metanol daging buah mahkota dewa yaitu 127,983 ppm dengan aktivitas antioksidan sedang.

\section{SARAN}

Perlu dilakukan penelitian lanjutan tentang aktivitas antioksidan dengan jenis pelarut yang berbeda dan juga isolasi senyawa dari ekstrak daging buah mahkota dewa untuk diketahui bioaktivitas nya.

\section{DAFTAR PUSTAKA}

Agustina, W., Nurhamidah., \& Handayani, D., 2017. Skrining Fitokimia dan Aktivitas Antioksidan Beberapa Fraksi Dari Kulit Batang Jarak (Ricinus communis L.). Jurnal Pendidikan dan Ilmu Kimia. 1(2), 117-122.

Arjadi, I., \& Mustofa. 2017. Ektrak Daging Buah Mahkota Dewa Meregenerasi Sel Pulau Langerhans Pada Tikus Putih Diabetes. Biogenesis. 5(1), 27-33.

Artanti, A.N., \& Lisnasari, R., 2018. Uji Aktivitas Antioksidan Ektrak Ethanol Daun Family Solanum Menggunakan Metode Reduksi Radikal Bebas DPPH. Journal of Pharmaceutical Science and Clinical Research. (02), 62-69.

Candrarisna, M., \& Kurnianto, A., 2018. Aktivitas Ekstrak Kulit Mahkota Dewa (Phaleria macrocarpa) Sebagai Teraupetik Diabetes Mellitus Terhadap Glukosa Darah, Leukosit dan Hemoglobin pada Tikus yang Diinduksi Aloksan, Jurnal Ilmiah Kedokteran Wijaya Kusuma. 7(1) 38-50.

Endarini, L. H. 2016. Farmakognisi dan Fitokimia. Badan Pengembangan dan Pemberdayaan Sumber Daya Manusia Kesehatan, Jakarta.

Fiana, N., \& Oktaria, D., 2016. Pengaruh Kandungan Saponin dalam Daging Buah Mahkota Dewa (Phaleria macrocarpa) terhadap Penurunan Kadar Glukosa Darah, MAJORITY. 5(4), 128-132. 
Khotimah, K., 2016. Skrining Fitokimia Dan Identifikasi Metabolit Sekunder Senyawa Karpain Pada Ekstrak Metanol Daun Carica pubescens Lenne dan K.Koch Dengan LC/MS (Liqiud Chromatograph-tandem Mass Spectrometry), Skripsi. Malang, Fakultas Sains Dan Teknologi, UIN.

Kumalaningsih, S. (2006). Antioksidan Alami Penangkal Radikal Bebas, Sumber Manfaat, Cara Penyediaan dan Pengolahan. Surabaya: Trubus Agrisarana.

Ma'ruf, M. T., Setiawan, S., \& Putra, B. P. D. (2017). Aktivitas Antibakteri Ekstrak Buah Mahkota Dewa (Phaleria Macrocarpa) Terhadap Staphylococcus aureus. Interdental: Jurnal Kedokteran Gigi, 13(2), 16-23.

Mbaoji, F. N., Ezike, A. C., Nworu, C. S., Onyeto, C. A., Nwabunike, I. A., Okoli, I. C., \& Akah, P. A., 2016. Antioxidant And Hepatoprotective Potentials Of Stemonocoleus Micranthus Harms (Fabaceae ) Stem Bark Extract.

Munte, N., \& Lubis, R., 2016. Skrining Fitokimia dan Antimikroba Ekstrak Daun Kirinyuh terhadap Bakteri Staphylococcus Aureus Dan Escherichia Coli. BIOLINK (Jurnal Biologi Lingkungan Industri Kesehatan), 2(2), 132-140.

Molyneux, P. 2004. The Use Of Stable Free Radical Diphenylpicrylhidrazyl (DPPH) For Estimating Antoxidant Activity, Songklanakarin, J. Sci.Technol. 26 (2), 211-219.

Parwati, N.K.F., Napitupulu, N., \& Diah, A.W.M., 2014. Uji Aktivitas Antioksidan Ekstrak Daun Binahong (Anredera Cordifolia (Tenore) Steenis) Dengan 1,1Difenil-2-Pikrilhidrazil (DPPH) Menggunakan Spektrofotometri UV-VIS, Jurnal Akademi Kimia. 3(4), 206-213.

Putri, A. A. S. \& Hidajati, N. 2015. Uji Aktivitas Antioksidan Senyawa Fenolik Ekstrak Metanol Kulit Batang Tumbuhan Nyiri Batu (Xylocarpus moluccensis). Unesa Journal of Chemistry, 4(1), 1-6.

Purwanto, D., Bahri, S., \& Ridhay, A., 2017. Uji Aktivitas Antioksidan Ekstrak Buah Purnajiwa (Kopsia arborea Blume.) Dengan Berbagai Pelarut, Jurnal Riset Kimia Kovalen. 3(1), 24-32.

Sukainah, A. S., Praja P., \&Gufran D. D., 2017. The QualitativeAnalysis, Antioxidant Test AndToxicity Test On Extract Of LeavesMangrove "Api-Api" (Avicennia. Sp). Asian Journal of Microbiology. Biotechnology \& Environmental Sciences Paper. (19) 290-295

Vijayanand, S., \& Thomas, A. S. 2016. Screening of Michelia champacca and Muntingia calabura extracts for potential Bioactives. International Journal of Pharma Sciences and Research 7(6), 266-273.

Yulianti, N.W.D., \& Arijana, I.G.K.N. 2016. Pengaruh Ekstrak Etanol Daging Buah Mahkota Dewa (Phaleria macrocarpa) Terhadap Viabilitas Sel Limfosit Pada Kultur PBMC Yang Dipapar $\mathrm{H}_{2} \mathrm{O}_{2} 3 \%$. E-Jurnal Medika, 5(8), 1-5. 